\title{
Exigências de energia de animais Nelore puros e mestiços com as raças Angus e Simental ${ }^{1}$
}

\author{
Marcos Inácio Marcondes ${ }^{2}$, Sebastião de Campos Valadares Filho ${ }^{3}$, Ivanna Moraes de \\ Oliveira ${ }^{2}$, Mário Fonseca Paulino ${ }^{3}$, Pedro Veiga Rodrigues Paulino ${ }^{3}$, Edenio Detmann ${ }^{3}$, \\ Luiz Fernando Costa e Silva ${ }^{4}$
}

\author{
${ }^{1}$ Pesquisa financiada pela Fundação de Amparo à Pesquisa de Minas Gerais (FAPEMIG)/Conselho Nacional de Pesquisa (CNPq). \\ 2 Doutorando em Zootecnia-DZO-UFV. \\ 3 Universidade Federal de Viçosa, Viçosa-MG. \\ ${ }^{4}$ Mestrando em Zootecnia - DZO-UFV.
}

RESUMO - Objetivou-se com este trabalho estimar as exigências nutricionais de energia líquida e metabolizável de animais Nelore, Nelore-Angus e Nelore-Simental, as eficiências de uso da energia metabolizável para ganho e mantença e a eficiência de deposição de energia na forma de proteína e gordura. Foram utilizados 69 animais (23 Nelore, 23 Nelore-Angus e 23 NeloreSimental): quatro animais de cada grupo genético (12 no total) foram abatidos antes do início do experimento como gruporeferência e nove foram separados para um ensaio de digestibilidade. Os animais restantes foram divididos em três dietas (ofertas de concentrado na proporção de 1 ou $2 \%$ do peso corporal obtido com consumo à vontade ou correspondente a $1 \%$ da exigência de mantença). Ao final todos animais foram abatidos e a composição corporal e o peso de corpo vazio (PCVZ) determinados. As exigências líquidas de energia foram estimadas pela equação da energia retida em função do PCVZ ${ }^{0,75}$ e ganho de peso de corpo vazio (GPCVZ). Foram estimadas as exigências de energia líquida e metabolizável para mantença pela equação da produção de calor em função do consumo de energia metabolizável. Houve efeito do teor de concentrado da dieta sobre a relação peso corporal:PCVZ, assim como para a relação ganho de peso corporal:GPCVZ. A exigência diária de energia líquida para mantença de animais Nelore, Nelore-Angus ou Nelore-Simental é de 75,8 kcal/PCVZ ${ }^{0,75}$ e a de energia metabolizável, de 112,82 kcal/PCVZ ${ }^{0,75}$. As eficiências de uso da energia metabolizável para ganho e mantença são de 41,22 e 67,19\%, respectivamente, e as eficiências de deposição da energia na forma de proteína e gordura, 26,71 e $75,43 \%$, respectivamente.

Palavras-chave: eficiência de uso da energia, energia líquida, energia metabolizável, exigências, terminação

\section{Energy requirements of Nellore purebred and crossbreed with Angus and Simmental}

ABSTRACT - The objective of this work was to estimate the nutritional requirements of net and metabolizable energy of Nellore, Nellore-Angus and Nellore Simmental cattle, as well as the efficiency of utilization of metabolizable energy for gain and maintenance and efficiency of energy deposition in the form of protein and fat. It was used 69 animals (23 Nellore, 23 Nellore-Angus and 23 Nellore-Simmental): four animals from each genetic group (12 in total) were slaughtered before the beginning of the experiment as the baseline group, and nine were used in a digestibility trial. The remaining animals were grouped in three dietary treatments (concentrate fed at 1 or $2 \%$ of body weight obtained with ad libitum intake or corresponding to $1 \%$ of the maintenance requirement). At the end of the experiment, all animals were slaughtered and body composition and empty body weight (EBW) were determined. The net energy requirements were estimated by using the equation of retained energt as a function of $\mathrm{EBW}^{0.75}$ and empty body weight gain (EBG). It was estimated the requirements of net and metabolizable energy for maintenance by using heat production equation in function of metabolizable energy intake. There was an effect of concentrate contents of the diet on the body weight:EBW ratio, as well as for body weight gain:EBG ratio. The net energy daily requirement for maintenance of Nellore, Nellore-Angus and Nellore-Simmental is $75.8 \mathrm{kcal} / \mathrm{EBW}^{0.75}$ and the metabolizable energy requirements for maintenance are $112.82 \mathrm{kcal} / \mathrm{EBW}^{0.75}$. The efficiency of metabolizable energy utilization for gain and maintenance are 41.22 and $67.17 \%$, respectively, and the energy retention efficiency as protein and fat are 26.71 and $75.43 \%$, respectively.

Key Words: efficiency of energy utilization, finishing, metabolizable energy, net energy, requirements 


\section{Introdução}

A maioria dos bovinos de corte do Brasil tem forte influência de sangue zebuíno. De acordo com Sainz et al. (2006), 80\% do gado nacional é composto de raças zebuínas. Contudo, o cruzamento industrial surgiu há algum tempo como forma de otimizar o desempenho e melhorar os índices de desfrute nas propriedades.

Esse maior potencial de crescimento de animais cruzados (Baker et al., 1989; Bulle et al., 2002) tem de ser aliado a um plano nutricional adequado dos animais, já que, geralmente, um maior desempenho está associado a maiores exigências de energia e proteína (NRC, 2000).

Entretanto, os sistemas mais utilizados do país para formulação de rações foram desenvolvidos em ambiente temperado e utilizando raças desse tipo de clima. O NRC (2000), AFRC (1993), CSIRO (2007) e o INRA (2007) são os sistemas de alimentação mais difundidos no mundo atualmente.

Existe uma proposta de exigências nutricionais para animais zebuínos criados em condições brasileiras (BR-CORTE, Valadares Filho et al., 2006), todavia não foram abordados nas pesquisas os efeitos de raças europeias sobre as exigências nutricionais desses animais.

Dessa forma, objetivou-se com este trabalho estimar as exigências nutricionais de energia líquida e metabolizável de animais puros da raça Nelore e seus cruzamentos com as raças Angus e Simental, bem como as eficiências de uso da energia metabolizável para ganho e mantença. Também foi objetivo do estudo estimar a eficiência de deposição de energia na forma de proteína e gordura nos diferentes grupos genéticos avaliados.

\section{Material e Métodos}

O trabalho foi realizado no Laboratório Animal da Universidade Federal de Viçosa e o experimento conduzido durante o período de maio a setembro de 2007. Foram utilizados 69 bovinos castrados de 18 meses, sendo 23 destes Nelore com 306,6 $\pm 27,0 \mathrm{~kg}$ de peso vivo (PV), $23 \mathrm{~F}_{1}$ Nelore-Angus (363,8 \pm 32 , 8 kg PV) e $23 \mathrm{~F}_{1}$ Nelore-Simental (367,2 $\pm 27,2 \mathrm{~kg} \mathrm{PV})$.

Do total, 12 animais (4 de cada grupo genético) foram designados como grupo referência e abatidos após o período de adaptação, 12 como grupo mantença e 9 (3 de cada grupo genético) foram destinados a um ensaio de digestibilidade. Todos os animais eram provenientes de um mesmo rebanho comercial, e foram pasto com suplementação durante a recria.
Os animais não pertencentes ao grupo referência foram divididos em três dietas ( 1 ou 2\% do peso corporal em oferta de concentrado e grupo mantença) de forma inteiramente casualizada em esquema fatorial $3 \times 3$ (três dietas e três grupos genéticos) com seis repetições para os animais alimentados à vontade e quatro para o grupo mantença.

Após um período de adaptação de 30 dias, onde todos os animais receberam uma dieta composta por $55 \%$ silagem de milho e $45 \%$ de concentrado, o grupo referência foi abatido e determinado o peso de corpo vazio (PCVZ) dos animais.

Após o abate do grupo referência, aqueles animais que foram designados a receber $2 \%$ do peso corporal em concentrado passaram uma semana recebendo $1,5 \%$ do peso vivo (PV) em concentrado e mais uma semana recebendo $2 \%$ do $\mathrm{PV}$ em concentrado para adaptação à dieta. Os animais que foram designados a receber $1 \%$ do PV em concentrado iniciaram com sua dieta imediatamente após o abate do grupo referência.

Os animais em mantença também iniciaram seu tratamento após o abate do grupo referência. Esses animais foram alimentados com 1,1\% do peso vivo (PV) em matéria seca, e foram alimentados com a mesma dieta fornecida aos animais que receberam $1 \%$ do PV em concentrado. Ao término dessa segunda semana, todos animais foram pesados para início do primeiro período experimental. Esse período de adaptação à dieta foi chamado de segunda adaptação.

Os animais foram mantidos em baias individuais, com piso de concreto, providas de comedouro e bebedouro de concreto, com área total de $30 \mathrm{~m}^{2}$, dos quais $8 \mathrm{~m}^{2}$ de área coberta com telhas de amianto. As rações foram formuladas para que as dietas fossem isoproteicas (12,5\%), sendo os consumos estimados segundo Valadares Filho et al. (2006) e as exigências de macro e microminerais ajustadas de acordo com o NRC (2000). Os concentrados foram formulados para que a mesma ração fosse ofertada para ambos tratamentos, mudando apenas a relação milho e ureia+sulfato de amônia (Tabelas 1 e 2).

O experimento teve uma duração total de 131 dias, sendo 30 dias de adaptação às condições experimentais, 14 dias de adaptação à dieta ( 2 a adaptação), três períodos de 28 dias, mais 3 dias para o abate dos animais. Ao término do terceiro período, iniciou-se o abate dos animais, sendo abatidos seis animais por dia.

Os alimentos foram fornecidos duas vezes ao dia e ajustados de forma a manter as sobras em torno de 5 a $10 \%$ do fornecido, com água permanentemente à disposição dos animais. A dieta oferecida foi registrada diariamente, assim como foram coletadas amostras da silagem de milho, caroço de algodão, casca de soja e das sobras de cada animal. 
Tabela 1 - Composição química dos ingredientes utilizados na ração experimental

\begin{tabular}{|c|c|c|c|c|c|c|}
\hline Item & $\begin{array}{l}\text { Caroço de } \\
\text { algodão }\end{array}$ & $\begin{array}{l}\text { Casca } \\
\text { de soja }\end{array}$ & $\begin{array}{l}\text { Farelo } \\
\text { de soja }\end{array}$ & Milho & $\begin{array}{l}\text { Silagem } \\
\text { de milho }\end{array}$ & $\begin{array}{l}\text { Mistura } \\
\text { mineral }\end{array}$ \\
\hline Matéria seca, \%MS & 91,18 & 88,68 & 88,61 & 88,38 & 28,95 & - \\
\hline Matéria orgânica, \%MS & 96,91 & 96,19 & 94,04 & 98,97 & 93,32 & - \\
\hline Proteína bruta (PB), \%MS & 23,92 & 11,85 & 49,46 & 8,91 & 7,13 & - \\
\hline Proteína insolúvel em detergente neutro/PB, \% $\mathrm{PB}$ & 12,79 & 40,10 & 11,68 & 29,72 & 19,55 & - \\
\hline Extrato etéreo, \%MS & 15,75 & 1,05 & 1,48 & 3,36 & 2,44 & - \\
\hline Fibra em detergente neutro (FDN), \%MS & 49,63 & 67,43 & 17,58 & 21,95 & 52,48 & - \\
\hline FDN isenta de cinzas e proteína, \%MS & 45,68 & 61,68 & 11,17 & 18,78 & 49,13 & - \\
\hline Carboidratos não-fibrosos, \%MS & 11,56 & 21,62 & 31,93 & 67,92 & 34,62 & - \\
\hline FDN indigestível, \%MS & 20,47 & 6,32 & 2,60 & 3,07 & 19,60 & - \\
\hline FDA indigestível, \%MS & 16,27 & 3,22 & 1,04 & 1,14 & 10,61 & - \\
\hline Fósforo, \%MS & 0,94 & 0,20 & 1,02 & 0,50 & 0,36 & 15,57 \\
\hline Cálcio, \%MS & 0,31 & 0,81 & 0,56 & 0,25 & 0,36 & 31,54 \\
\hline Magnésio, \%MS & 0,29 & 0,27 & 0,35 & 0,11 & 0,11 & 0,66 \\
\hline Sódio, \%MS & 0,16 & 0,17 & 0,11 & 0,11 & 0,14 & 0,23 \\
\hline Potássio, \%MS & 1,17 & 1,31 & 2,13 & 0,47 & 1,28 & 0,40 \\
\hline
\end{tabular}

Tabela 2 - Composição dos concentrados e das dietas, com base na matéria seca

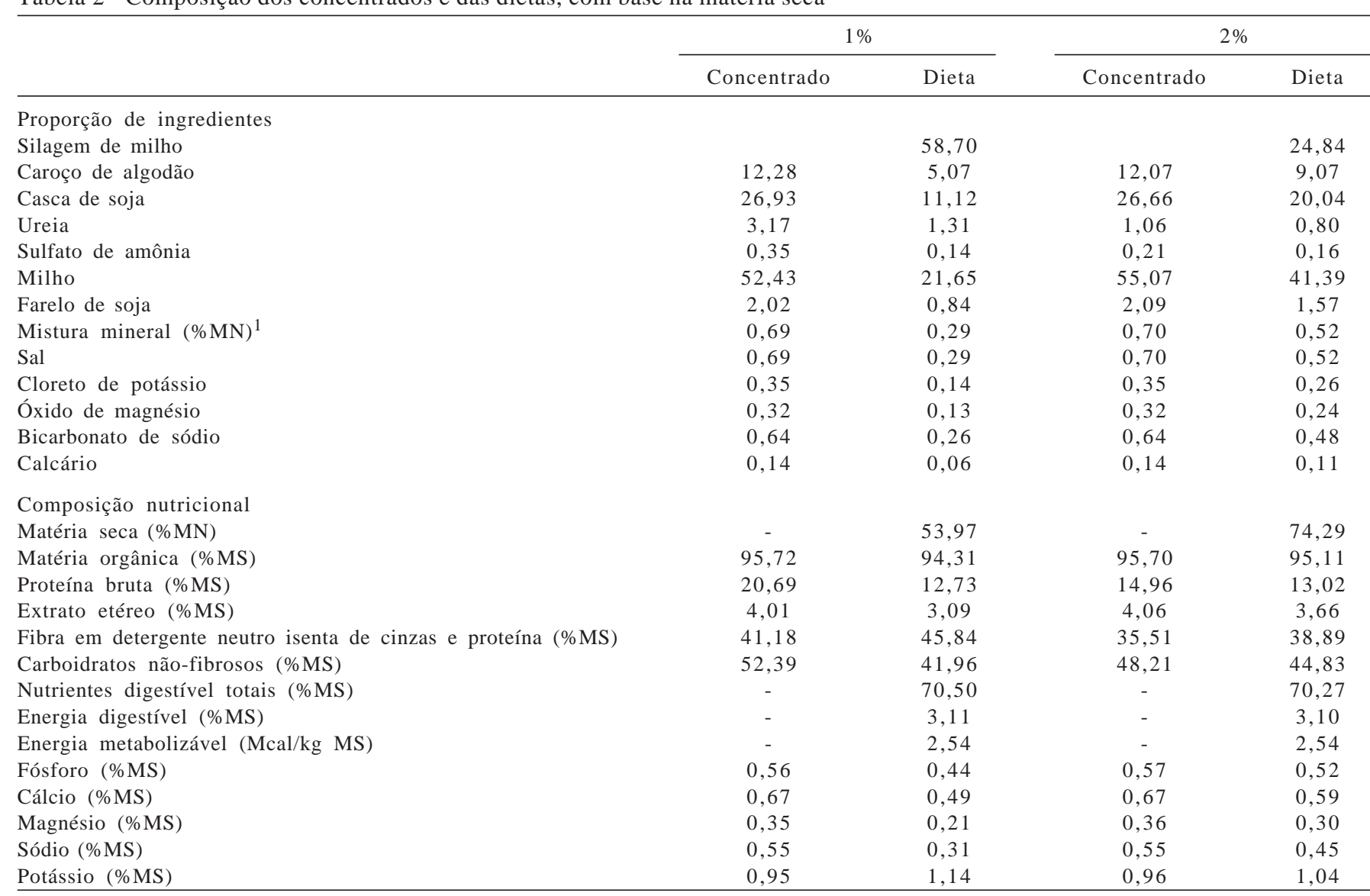

${ }^{1}$ Composição: cálcio - 24,0\%; fósforo - 17,4\%; cobalto - 100,0 ppm; cobre - 1.250,0 ppm; ferro - 1.795,0 ppm; manganês - 2.000,0 ppm; selênio - 15,0 ppm; zinco 5.270,0 ppm; iodo - 90,0 ppm.

No primeiro período, a oferta de concentrado foi corrigida semanalmente com base no desempenho dos animais na segunda adaptação, e no segundo e terceiro períodos esse ajuste foi feito, também semanalmente, com base no desempenho dos períodos anteriores.
As amostras de sobras e alimentos fornecidos foram agrupadas em amostras compostas semanais, proporcionais à matéria pré-seca, e foi determinada a matéria seca de todas essas compostas para obtenção do consumo de matéria seca. A partir das amostras compostas semanais foi elaborada 
uma amostra composta por cada período de 28 dias. Nas amostras compostas de cada período foi determinada sua composição química.

A descrição detalhada das análises química é apresentada por Marcondes et al. (2011). O consumo de energia metabolizável(CEM) foi calculado multiplicando o consumo de cada nutriente pelo seu respectivo coeficiente de digestibilidade, e posteriormente pelo seu valor calórico. A conversão de energia digestível (ED) em energia metabolizável(EM) foi conforme proposto pelo NRC (2000), segundo a equação $\mathrm{EM}=0,82 \times \mathrm{ED}$.

As amostras coletadas foram pré-secas em estufa ventilada a $65^{\circ} \mathrm{C}$ por 72 horas e moídas em moinho com peneira de malha de $1 \mathrm{~mm}$ por 10 minutos, sendo o remanescente do moinho adicionado à amostra moída.

Antes dos abates, os animais foram submetidos a jejum de sólidos de 16 horas. O abate foi realizado via insensibilização e secção da jugular para sangramento total, seguido de lavagem do aparelho gastrintestinal (rúmen, retículo, omaso, abomaso e intestinos delgado e grosso) para determinação do peso de corpo vazio (PCVZ).

A relação média obtida entre o PCVZ e o peso corporal do grupo referência foi utilizada para a estimativa do PCVZ inicial dos animais que permaneceram em alimentação. Após o abate, as duas meia carcaças resfriadas em câmara a $0-4^{\circ} \mathrm{C}$, durante 18 horas.

Todas as meias-carcaças direitas foram dissecadas em ossos, gordura e músculo, sendo que músculo e gordura foram moídos separados e posteriormente feita uma amostra composta proporcional à sua presença na carcaça. Já os ossos foram separados em ossos longos, vértebras e costelas, amostrados e serrados, sendo feita uma composta de ossos da carcaça, também proporcional ao seu peso na carcaça.

O rúmen, retículo, omaso, abomaso, intestino delgado, intestino grosso, gordura interna, mesentério, fígado, coração, rins, pulmão, língua, baço, carne industrial e aparas (esôfago, traquéia e aparelho reprodutor) foram triturados em triturador industrial por 20 minutos, constituindo uma amostra composta de vísceras e órgãos.

As amostras de sangue foram coletadas durante a sangria, acondicionadas em recipiente de vidro e levadas à estufa de ventilação forçada, a $65^{\circ} \mathrm{C}$, durante 72 horas, para determinação do teor de matéria seca (MS), e moídas em moinho de bola.

Aleatoriamente foram escolhidos dois animais de cada tratamento (dieta $\times$ grupo genético), que tiveram suas cabeças e pés amostrados. A composição média da cabeça e pés desses animais para cada tratamento foi utilizada como base de cálculo da composição dos animais que não tiveram seus pés e cabeça amostrados.

Com exceção do sangue, todas as amostras (órgãos+ vísceras, músculo+gordura, ossos, tecido mole e couro) foram liofilizadas por 72 a 96 horas para determinação da matéria pré-seca gordurosa (MSG). Posteriormente, as amostras foram submetidas a um pré-desengorduramento (MSPD) por extração por éter de petróleo no aparelho Soxhlet por 6 horas. Em seguida, foram moídas em moinho de bola, para posteriores determinações de nitrogênio total e extrato etéreo, conforme Silva \& Queiroz (2002). A gordura removida no pré-desengorduramento foi calculada pela diferença entre a matéria seca gordurosa e a matéria seca pré-desengordurada.

A determinação da energia corporal foi obtida a partir dos teores corporais de proteína e gordura e seus respectivos equivalentes calóricos de 5,6405 e 9,3929 (ARC, 1980), respectivamente, conforme a equação preconizada pelo ARC (1980). Os conteúdos de energia no corpo dos animais de cada tratamento, e para todos os tratamentos em conjunto, foram estimados por meio dos conteúdos corporais de energia dos animais em desempenho e referência, em função do PCVZ, conforme o modelo: $\mathrm{CE}=\mathrm{a} \times \mathrm{PCVZ}^{\mathrm{b}}$, em que CE é o conteúdo de energia corporal (Mcal), PCVZ é o peso de corpo vazio e ‘a' e ‘b’ são parâmetros da regressão.

A partir dos parâmetros da regressão, as exigências líquidas de energia por quilo de ganho de peso de corpo vazio foram estimadas pela derivada da equação acima, segundo o modelo:

$\mathrm{EL}_{\mathrm{g}}=\mathrm{a} \times \mathrm{b} \times \mathrm{PCVZ}^{\mathrm{b}-1}$, em que $\mathrm{EL}_{\mathrm{g}}$ é a exigência de energia líquida para ganho (Mcal/kgGPCVZ).

Foram ajustadas equações de regressão entre a energia retida (ER) e o ganho diário de PCVZ, para determinado PCVZ metabólico ( $\left.\mathrm{kg}^{0,75}\right)$, nos animais em desempenho, utilizando o modelo: $\mathrm{ER}=\mathrm{a} \times \mathrm{PCVZ}^{0,75} \times \mathrm{GPCVZ}^{\mathrm{b}}$, em que ER é a energia retida (ER, Mcal/PCVZ 0,75/dia) e ‘a' e 'b’ são coeficientes da regressão.

As exigências de energia metabolizável para mantença $\left(E M_{m}\right)$ foram estimadas utilizando os animais em desempenho e mantença a partir da relação entre a energia retida (ER) e o CEM, segundo o modelo: $\mathrm{ER}=\beta_{1} \times \mathrm{CEM}+\beta_{0}$, em que $\beta_{1}$ representa a eficiência de uso da energia metabolizável para ganho de peso.

Para obtenção dos parâmetros $\beta_{0}$ e $\beta_{1}$ da equação acima, foi utilizado o método da regressão ortogonal, conforme preconizado por Fuller (1987), uma vez que existem erros associados às duas variáveis (ER e CEM), de acordo com as equações: 


$$
\begin{aligned}
& \beta_{0}=\overline{\mathrm{Y}}-\beta_{1} \times \overline{\mathrm{X}} \\
& \beta_{1}=\frac{\sigma_{\mathrm{y}}^{2}-\sigma_{\mathrm{x}}^{2}+\sqrt{\left(\sigma_{\mathrm{y}}^{2}-\sigma_{\mathrm{x}}^{2}\right)^{2}+4 \times \sigma_{\mathrm{xy}}^{2}}}{2 \times \sigma_{\mathrm{xy}}}
\end{aligned}
$$

em que $\overline{\mathrm{X}}=$ média do consumo de energia metabolizável (Mcal/kgPCVZ ${ }^{0,75} / \mathrm{d}$ ), $\overline{\mathrm{Y}}=$ médiadaenergia(Mcal/kgPCVZ ${ }^{0,75} / \mathrm{d}$ ), $\sigma_{\mathrm{x}}^{2}=$ variância de $\mathrm{X} ; \sigma_{\mathrm{y}}^{2}=$ variância de $\mathrm{Y} ; \sigma_{\mathrm{xy}}=$ covariância entre X e Y.

Igualando-se a energia retida a zero na equação acima, foi obtido o consumo de energia metabolizável, em que a retenção de energia é nula, representando, dessa forma as $E M_{m}$. O $\beta_{1}$ foi definido como a eficiência de uso da energia metabolizável para ganho $\left(\mathrm{k}_{\mathrm{g}}\right)$.

Também com o mesmo grupo de animais, foram estimadas as exigências de energia líquida para mantença, a partir do intercepto da regressão exponencial entre a produção de calor (PC) e o CEM. Pelo método interativo foi determinado o ponto onde o CEM e a PC se igualam, sendo esse valor uma segunda forma de estimar as exigências de $\mathrm{EM}_{\mathrm{m}}$. O modelo utilizado foi: $\mathrm{PC}=\mathrm{b}_{0} \times \mathrm{e}^{\mathrm{b}}{ }_{1} \times \mathrm{CEM}$, em que PC é a produção de calor (Mcal/PCVZ ${ }^{0,75}$ ), CEMé o consumo diário de energia metabolizável (Mcal/PCVZ ${ }^{0,75}$ ), b 0 e b 1 são parâmetros da regressão e 'e' é o número de Euler.

A eficiência de utilização da energia metabolizável para mantença $\left(k_{m}\right)$ foi obtida a partir da relação entre as exigências líquidas e metabolizáveis de energia para mantença obtidas pelos modelos avaliados. Para cálculo das eficiências parciais de uso da energia metabolizável para síntese de gordura e proteína, foi construída a equação:

$\mathrm{CEM}=\beta_{0}+\beta_{1} \times \Delta_{\text {prot }}+\beta_{2} \times \Delta_{\text {gord }}$,

em que CEM = consumo diário de energia metabolizável $\left(\mathrm{Mcal} / \mathrm{PCVZ}^{0,75}\right) ; \Delta_{\text {prot }}$ e $\Delta_{\text {gord }}=$ variações de energia corporal em função da proteína e gordura (Mcal/PCVZ, ${ }^{0,75}$ ), respectivamente; e $\beta_{0} ; \beta_{1}$ e $\beta_{2}=$ coeficientes da regressão múltipla.

O intercepto $\left(\beta_{0}\right)$ da equação representa uma terceira forma de estimativa das exigências de energia metabolizável para mantença (Mcal/PCVZ ${ }^{0.75}$ ), e os inversos dos coeficientes $\beta_{1}$ e $\beta_{2}$ representaram as eficiências de deposição da energia na forma de proteína e gordura ( $\mathrm{k}_{\text {prot }} \mathrm{e} \mathrm{k}_{\text {gord }}$ ), respectivamente.

Os modelos de conteúdo corporal, energia retida em função do GPCVZ e produção de calor, com seus respectivos coeficientes, foram testados pelo teste de identidade de modelos de Regazzi \& Silva (2004). Já o modelo da energia retida em função do CEM, os modelos de cálculo de PCVZ e GPCVZ foram testados pela identidade de modelos de Regazzi (1999) e o CEM em função da $\Delta_{\text {prot }}$ e $\Delta_{\text {gord }}$ foram testados pelo proc Mixed do SAS. Para todos os testes foi utilizado 5\% como nível crítico para identificar efeitos de grupo genético sobre as exigências de energia dos animais.

\section{Resultados e Discussão}

A relação média entre PV e PCVZ foi de 0,9171. Os dados de PCVZ foram contrastados aos de PV por meio de uma regressão linear sem intercepto, sendo testados os efeitos de grupo genético e dieta, assim como sua interação. Não houve efeito da interação grupo genético $x$ dieta $(P>0,05) \mathrm{e}$ do grupo genético, entretanto houve efeito das dietas sobre a relação. Os modelos por dieta são demonstrados abaixo.

1\% do PV: $P C V Z=0,9143(0,0767) \times P V J$

$2 \%$ do $P V: P C V Z=0,9312(0,0737) \times P V J$

onde PCVZ é o peso de corpo vazio (kg) e PVJ é o peso vivo é jejum (kg).

O BR-CORTE (2006) e o NRC (2000) apresentaram valores fixos para a relação PVJ/PCVZ de 0,896 e 0,891, respectivamente. Entretanto, de acordo com o NRC (2000), essa relação poderia variar de 85 a 95\%. Chizzotti et al. (2008), usando a metanálise de dados de animais zebuínos e cruzados criados no Brasil, apresentaram uma relação PVJ/PCVZ de acordo a equação: PCVZ = -15,6 + 0,928 $\times$ PVJ; e também observaram que o intercepto não foi diferente de zero, portanto muito semelhante ao modelo proposto nesse trabalho.

A relação GMD/GPCVZ média foi de 0,9242 , valor próximo daqueles reportados pelo BR-CORTE (2006), NRC(2000) e Chizzotti et al. (2008), de 0,933; 0,951 e 0,961, respectivamente. Quando os dados de GPCVZ foram regredidos em função do ganho médio diário, observou-se efeito dos tratamentos ( 1 ou $2 \%$ do PV em oferta de concentrado) e de grupo genético, todavia não foi observado efeito de interação grupo genético $\times$ tratamento:

Nelore e Nelore-Simental: GPCVZ $=0,8736( \pm 0,0167) \times$ GMD

$1 \%$ do PV: $\mathrm{GPCVZ}=0,8806( \pm 0,0231) \times \mathrm{GMD}$

$2 \%$ do PV: GPCVZ $=0,9639( \pm 0,0220) \times \mathrm{GMD}$

em que GPCVZ é o ganho de peso de corpo vazio (kg/dia) e GMD é o ganho médio diário ( $\mathrm{kg} / \mathrm{dia})$. Os resultados encontrados para Nelore-Angus demonstram que esses animais tiveram GPCVZ semelhante ao ganho médio diário. As equações que descrevem o conteúdo de energia corporal estimadas foram:

Nelore: Energia corporal $(\mathrm{Mcal})=0,0525 \times \mathrm{PCVZ}^{1,6649}$

Nelore-Angus: Energia corporal $(\mathrm{Mcal})=0,0188 \times$ PCVZ $^{1,8222}$

Nelore-Simental: Energia corporal $($ Mcal $)=0,0342 \times$ PCVZ $^{1,7249}$

em que PCVZ é o peso de corpo vazio. 
Não foram detectadas diferenças significativas entre os grupos $(\mathrm{P}>0,05)$, portanto foi estimada uma equação conjunta descrita como:

Energia corporal $($ Mcal $)=0,0611 \times$ PCVZ $^{1,6318}$

A partir das equações apresentadas, foram estimadas as exigências de energia líquida por quilo de ganho de peso de corpo vazio para diferentes pesos corporais (Tabela 3). Também foram representados as exigências sugeridas pelo BR-CORTE (2006) e NRC (2000) para fins de comparação (Tabela 3). Os dados evidenciam um aumento nas exigências de energia na medida em que aumenta o peso corporal dos animais. Esse fato ocorre devido ao aumento da maturidade dos animais, onde a deposição de proteína começa a diminuir e o metabolismo transfere o fluxo de energia para reservas corporais.

A falta de significância observada entre os grupos genéticos para as exigências de energia líquida indica que, apesar da alta heterose, animais zebuínos poderiam obter ganhos semelhantes aos mestiços se corretamente alimentados. Alguns trabalhos feitos em sistemas de pastagens e confinamentos mostram bons resultados para zebuínos em comparação a animais cruzados.

Leme et al. (2000), trabalhando com diversos grupos raciais em confinamento, encontraram maior ganho de animais $F_{1}$ South Devon-Nelore (1,37 kg/dia) em relação aos animais Nelore provindos de rebanho com programa de seleção genética $(0,77 \mathrm{~kg} / \mathrm{dia})$, porém não observaram diferença entre animais Nelore comerciais comparados com $\mathrm{F}_{1}$ Nelore-Hereford, $\mathrm{F}_{1}$ Nelore-Aberdeen Angus, $\mathrm{F}_{1}$ Nelore-Red Angus, $\mathrm{F}_{1}$ Nelore-Caracu, $1 / 4$ Simental-Nelore e $1 / 4$ Charolês-Nelore.

Já Cruz et al. (2009), em pastagem de Coastcross, obtiveram ganhos de animais Nelore e $F_{1}$ Nelore-Simental iguais quando suplementados com mistura mineral, diferindo de $F_{1}$ Nelore-Angus e $F_{1}$ Nelore-Canchim. Quando suplementados com concentrados, apenas os animais Nelore-Angus foram superiores aos demais.

O National Research Council (NRC, 2000) sugere que diferenças nas exigências de energia entre Bos taurus e Bos indicus poderiam ser mais evidenciadas pelas exigências de mantença, uma vez que zebuínos teriam exigência $10 \%$ menor para mantença em relação aos taurinos.

Os valores estimados a partir da equação para castrados das Tabelas Brasileiras de Exigências Nutricionais para Zebuínos (BR-CORTE, 2006) indicam valores superiores aos encontrados neste trabalho (Tabela 3 ), porém esses dados foram gerados com apenas 59 observações, quantidade maior que as utilizadas nesse trabalho.

Além disso, os valores do NRC (2000) obtidos com animais taurinos são ainda maiores que aqueles do BRCORTE. Dessa forma, devido à baixa quantidade de trabalhos encontrados na literatura comparando exigências nutricionais de animais zebuínos e seus cruzamentos, mais estudos ainda precisam ser desenvolvidos para que se encontre uma conclusão mais adequada sobre desenvolver, ou não, tabelas de exigência conjuntas ou separadas para animais zebuínos e cruzamentos industriais.

Os valores de energia retida foram contrastados com aqueles de ganho de peso de corpo vazio, conforme a equação:

$\mathrm{RE}_{\mathrm{L}}(\mathrm{Mcal} / \mathrm{dia})=0,0623( \pm 0,0023) \times \mathrm{PCVZ}^{0,75} \times \mathrm{GPCVZ}^{1,0356}$ $( \pm 0,1607)$

Não foi observado efeito de grupo genético $(\mathrm{P}>0,05)$ sobre os coeficientes do modelo descrito acima, o que confirma a semelhança de exigências de energia líquida entre os animais Nelores e seus mestiços. O BR-CORTE (2006) relata, para animais zebuínos puros, e Chizzotti et al. (2008), para animais zebuínos puros e mestiços, interceptos para animais machos castrados bastante semelhantes aos deste trabalho (0,0608 e 0,0700, respectivamente). No entanto, os valores dos expoentes do GPCVZ foram maiores (1,0996 e 1,070, respectivamente), assim como aquele apresentado pelo NRC (2000), de 1,0970, indicando exigências de energia líquida ligeiramente maiores nesses trabalhos, confirmando os dados apresentados (Tabela 3).

Chizzotti et al. (2008) também não encontraram efeito de grupo genético sobre as exigências de energia líquida para bovinos em terminação. Freitas et al. (2006) avaliaram as exigências de animais Nelore, Nelore-Angus, Nelore-

Tabela 3 - Exigências de energia líquida para ganho (Mcal/kgGPCVZ) de animais de diferentes grupos genéticos em função dos pesos corporais

\begin{tabular}{cccccc}
\hline Peso corporal & Nelore & Nelore-Angus & Nelore-Simental & Conjunta & BR-CORTE \\
\hline 250 & 3,249 & 2,988 & 3,033 & 3,090 & 3,582 \\
300 & 3,668 & 3,472 & 3,461 & 3,467 & 4,107 \\
350 & 4,064 & 3,941 & 3,870 & 3,822 & 4,611 \\
400 & 4,441 & 4,398 & 4,264 & 4,159 & 5,096 \\
450 & 4,803 & 4,845 & 4,644 & 4,480 & 5,567 \\
500 & 5,151 & 5,284 & 5,012 & 4,788 & 6,025 \\
550 & 5,488 & 5,715 & 5,371 & 5,085 & 6,323 \\
\hline
\end{tabular}


Simental e Nelore-Pardo-Suíço e também não notaram diferenças entre os grupos genéticos para energia líquida.

O National Research Council (NRC, 2000) sugere que se faça a correção do peso dos animais para um mesmo conteúdo de gordura corporal antes de proceder às analises de energia retida em função do ganho de peso de corpo vazio. Tedeschi et al. (2002) sugerem que esse valor seja corrigido para um teor de $22 \%$ de extrato etéreo no corpo dos animais. De acordo com os dados obtidos nesse experimento, os pesos de corpo vazio referência para os grupos genéticos estudados ao nível de $22 \%$ de gordura seriam de 435, 480 e $495 \mathrm{~kg}$ para Nelore, Nelore-Angus e Nelore-Simental, respectivamente. Para a correção dos pesos corporais para um mesmo peso equivalente utilizou-se a equação sugerida pelo NRC (2000):

$P C V Z_{e q}=\frac{P C V Z \times P C V Z_{\text {ref }}}{P C V Z_{22 \% E E}}$

em que PCVZeq = peso de corpo vazio equivalente; $\mathrm{PCVZ}_{\text {ref }}=$ peso referência utilizado para todos animais em que o PCVZeq teria $22 \%$ de EE; e PCVZ $22 \%$ EE $=$ PCVZ com $22 \%$ de extrato etéreo dos diferentes grupos genéticos (435 kg para Nelore, 480 para Nelore-Angus e 495 para Nelore-Simental).

O peso de corpo vazio referência utilizado pelo NRC (2000) é de $478 \mathrm{~kg}$, entretanto, como os animais desse trabalho continham um grau de sangue predominante de zebuínos, foi adotado o PCVZ $\mathrm{Pef}_{\text {de }} 450 \mathrm{~kg}$.

Quando foi feita a correção do peso dos animais para o mesmo teor de gordura no corpo vazio, observou-se mais uma vez que não houve efeito dos grupos genéticos sobre as exigências líquidas de energia, ficando a equação apresentada abaixo:

$\mathrm{EL}_{\mathrm{g}}(\mathrm{Mcal} / \mathrm{dia})=0,0644( \pm 0.003) \times \mathrm{PCVZ}_{\text {eq }}{ }^{0,75} \times$ GPCVZ $^{1,0467}( \pm 0.189)$

em que $\mathrm{EL}_{\mathrm{g}}=$ exigências de energia líquida para ganho; $\mathrm{PCVZ}_{\text {eq }}=$ peso de corpo vazio equivalente; e GPCVZ = ganho de peso de corpo vazio.

O expoente do GPCVZ ficou mais próximo dos dados encontrados na literatura, sugerindo que a correção do PCVZ para um mesmo peso a $22 \%$ de gordura é importante e deve ser utilizada.

Apesar de os modelos do NRC (2000) indicarem exigências de energia líquida maiores que os deste experimento, os dados da literatura comprovam grande proximidade entre as exigências de animais Bos taurus, Bos indicus e seus mestiços. Todavia parece não haver experimentos que contenham avaliações de animais puros Bos taurus e Bos indicus para que se comprove essa hipótese. Em relação aos animais cruzados, os dados deste trabalho, somados às observações encontradas na literatura (Chizzotti et al., 2008; Freitas et al., 2006), sugerem que a heterose não tem influência significativa nas exigências líquidas de energia.

De acordo com Dawson \& Steen (1998), a exigência de energia metabolizável para mantença pode ser definida como o consumo de energia metabolizável quando a energia retida é igual a zero.

Os modelos desenvolvidos para cada grupo genético apresentaram exigências de energia metabolizável para mantença $\left(\mathrm{EM}_{\mathrm{m}}\right)$ de 100,76; 82,15 e 93,66 kcal/PCVZ ${ }^{0,75} /$ dia para animais Nelore, Nelore-Angus e Nelore-Simental, respectivamente (Figura 1). Contudo, o teste de identidade de modelos não verificou diferenças significativas entre os mesmos $(\mathrm{P}>0,05)$.

De acordo com essa equação, as exigências diárias de energia metabolizável para mantença dos animais são de $98,97 \mathrm{kcal} / \mathrm{PCVZ}^{0,75}$. Esse valor está abaixo da maioria dos dados encontrados na literatura, como os de Chizzotti et al. (2008) de 112,0 kcal/PCVZ ${ }^{0,75}$, e o valor do BR-CORTE (2006) de 108,39 kcal/PCVZ ${ }^{0,75}$. Entretanto, é similar ao encontrado por Freitas et al. (2006) de 97,71 kcal/PCVZ ${ }^{0,75}$, que fez um estudo semelhante ao deste trabalho, mas com um grupo racial a mais (Nelore-Pardo-Suíço).

A inclinação do mesmo modelo gerado acima fornece a eficiência do uso da energia metabolizável para ganho de peso $\left(\mathrm{k}_{\mathrm{g}}\right)$, que foi de $41,22 \%$ neste experimento. Os valores de eficiência para cada grupo genético foram de 41,43; 38,53 e 40,37\% para Nelore, Nelore-Angus e Nelore-Simental, respectivamente. Entretanto, os mesmos não diferiram entre si pelo teste de identidade de modelos, sendo sugerido, o valor médio de eficiência para os três grupos raciais.

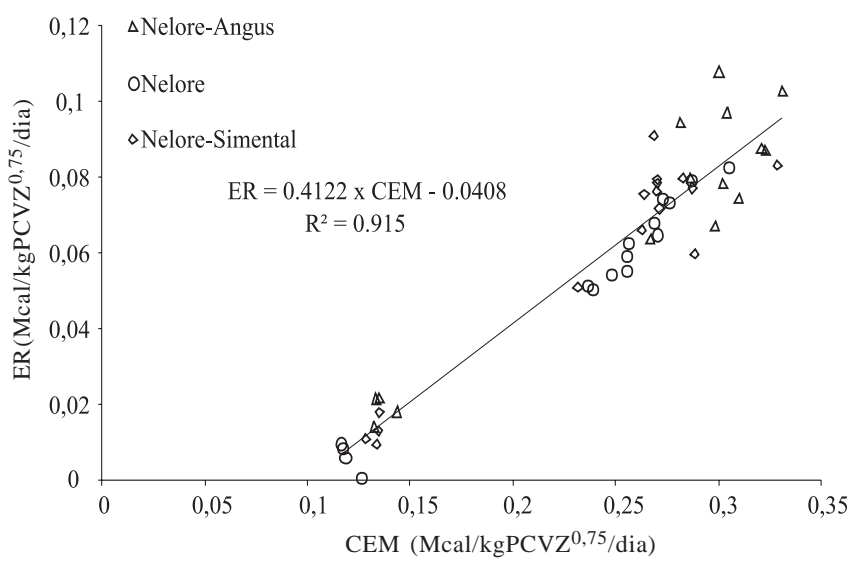

Figura 1 - Relação entre a energia retida e consumo de energia metabolizável de zebuínos puros e mestiços. 
Paulino (2006) encontrou valor médio de $\mathrm{k}_{\mathrm{g}}$ de $45 \%$ em animais Nelore de três classes sexuais e Tedeschi et al. (2002) encontraram valores de 45,9 e 49,7\% para machos Nelore não-castrados e castrados, respectivamente. Esses valores são superiores aos deste trabalho, no entanto, Freitas et al. (2006) encontraram eficiência de 40,78\% em condições experimentais semelhantes.

Esses dados sugerem maior eficiência de uso da energia metabolizável para ganho de animais Nelore em relação aos dados de animais mestiços. Entretanto, o BR-CORTE (2006) divide a eficiência de uso da energia metabolizável para ganho de acordo com a dieta recebida pelos animais. Segundo os autores, a eficiência de uso da energia metabolizável para ganho $\left(\mathrm{k}_{\mathrm{g}}\right)$ seria de $35 \%$ para animais recebendo menos de $50 \%$ de concentrado e de $47 \%$ para animais alimentados com dietas de alto valor energético.

Marcondes et al. (2011) fizeram a avaliação de desempenho e consumo deste experimento e não encontraram diferença na eficiência de ganho de peso em relação ao consumo de matéria seca desses animais. De acordo com os autores, níveis subclínicos de acidose podem ter interferido para a limitação de consumo dos animais com maior nível de concentrado, interferindo também na seletividade e limitando o consumo de nutrientes.

Tedeschi et al. (2004) e Chizzotti et al. (2008) propuseram modelos para estimar o k em função da retenção de energia na forma de proteína. De acordo com os modelos, quanto maior a participação da energia vinda da proteína no ganho, menor a eficiência de ganho dos animais. A partir das equações obtiveram-se eficiências de 52,26 e 65,22\%, respectivamente, valores esses maiores que a eficiência média encontrada neste trabalho (41,22\%). Assim, apesar de os modelos sugerirem um comportamento biológico esperado, é possível que tenham ainda que passar por processos de avaliação e reparametrização para que possam ser totalmente aplicáveis em condições práticas.

Existem outros métodos para estimar as exigências de energia para mantença. Atualmente o método mais aceito é aquele que relaciona a produção de calor (PC) e o consumo de energia metabolizável de forma exponencial. Nesse modelo, o intercepto da equação seria a exigência de energia líquida para mantença e o ponto em que a produção de calor e o consumo de energia metabolizável são iguais representa a exigência de energia metabolizável para mantença.

Foram estimadas essas equações para cada grupo genético:

Nelore-Simental: PC $($ Mcal/PCVZ $0,75 /$ dia $)=0,0738$ $( \pm 0,0048) \mathrm{e}^{3,6339}( \pm 0,2426) \times$ CEM

Nelore: PC $\left(\right.$ Mcal/PCVZ ${ }^{0,75} /$ dia $)=0,0753( \pm 0,0049)$ $\mathrm{e}^{3,6581( \pm 0,2514) \times \text { CEM }}$
Nelore-Angus: PC (Mcal/PCVZ $0,75 /$ dia $)=0,0716$ $( \pm 0,0045) \mathrm{e}^{3,6584( \pm 0,2099) \times \text { CEM }}$

em que PC é a produção de calor e CEM é o consumo de energia metabolizável (Mcal/PCVZ $0,75 /$ dia)

A partir da equações acima obtiveram-se exigências líquidas de energia líquida de 73,8; 75,3 e 71,6 kcal/PCVZ para animais Nelore-Simental, Nelore e Nelore-Angus, respectivamente. O teste de identidade de modelos não identificou efeito de grupo genético sobre as exigências de energia líquida. Dessa forma, foi formulada uma equação conjunta para todos os grupos raciais (Figura 2):

PC $\left(\right.$ Mcal $/ \mathrm{PCVZ}^{0,75} /$ dia $)=0,0758( \pm 0,0027) \mathrm{e}^{3,5299}$ $( \pm 0,1301) \times$ CEM

A exigência de energia líquida para mantença foi de $75,8 \mathrm{kcal} / \mathrm{PCVZ}^{0,75} /$ dia. O NRC (2000) preconiza um valor de $77 \mathrm{kcal} / \mathrm{PCVZ}^{0,75}$ para mantença e cita que animais zebuínos teriam cerca de $10 \%$ a menos de exigências, ou seja, $70 \mathrm{kcal} / \mathrm{kgPCVZ}{ }^{0,75}$. Percebe-seque ovalor 75,8 kcal/PCVZ ${ }^{0,75}$ está coerente com o proposto pelo NRC (2000), considerando que existia uma maioria de animais com sangue taurino e que a exigência de mantença ficou mais próxima ao valor $77 \mathrm{kcal} / \mathrm{PCVZ}^{0,75}$.

Chizzotti et al. (2008), também avaliando animais zebuínos puros e mestiços, encontraram um valor quase idêntico ao deste trabalho, de 75,0 kcal/kgPCVZ ${ }^{0,75}$. Já no BR-CORTE (2006) e em pesquisa realizada por Freitas et al. (2006) com animais zebuínos puros e mestiços, respectivamente, foram descritos valores um pouco maiores, de 78,9 e 79,0 kcal $/ \mathrm{PCVZ}^{0,75}$, respectivamente.

Pelo método interativo, estimaram-se as exigências de energia metabolizável para mantença no ponto em que a produção de calor se igualou ao consumo de energia metabolizável. Os valores de $\mathrm{EM}_{\mathrm{m}}$ para animais NeloreSimental, Nelore e Nelore-Angus foram de 110,09; 114,45 e $105,11 \mathrm{kcal} / \mathrm{kgPCVZ}^{0,75} /$ dia, respectivamente.

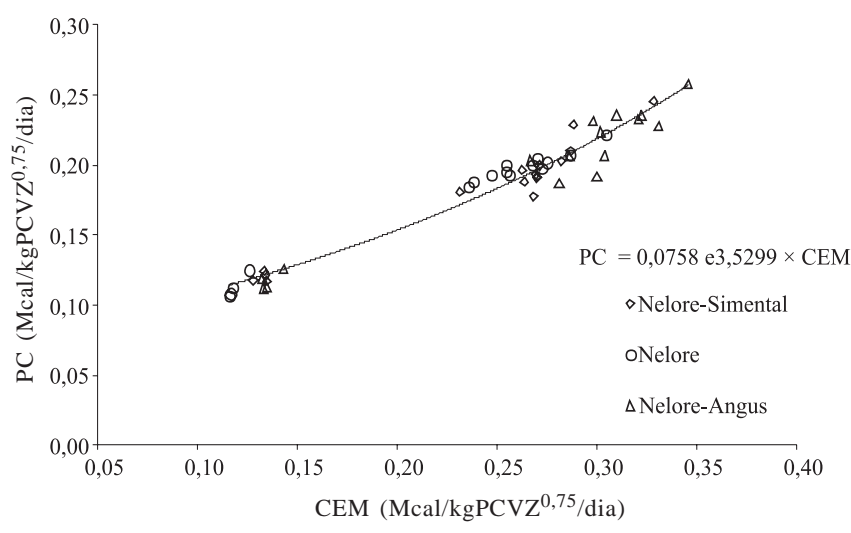

Figura 2 - Relação entre a produção de calor e consumo de energia metabolizável para os animais de três grupos genéticos 
Como não foi encontrada diferença significativa entre esses valores $(\mathrm{P}>0,05)$, obteve-se uma estimativa conjunta de $112,82 \mathrm{kcal} / \mathrm{kgPCVZ}^{0,75} /$ dia para o presente experimento. Assim como para a energia líquida, esse valor está dentro daquele encontrado na literatura em relação a animais zebuínos puros e cruzados (Tedeschi et al., 2002; BR-CORTE, 2006; Freitas et al. 2006; Chizzotti et al., 2008).

Conhecendo os valores de energia líquida e metabolizável para mantença, obtem-se a eficiência de uso da energia metabolizável para mantença $\left(\mathrm{k}_{\mathrm{m}}\right)$. Os valores de eficiência obtidos para animais Nelore-Simental, Nelore e Nelore-Angus foram de 66,65; 65,79 e 68,12\%. No entanto, como não houve diferença significativa entre esses valores, sugere-se adotar um valor conjunto de 67,19\% para esses três grupos raciais.

Freitas et al. (2006) e Chizzotti et al. (2008) também encontraram valores de $67 \%$ de eficiência em seus estudos com animais zebuínos e seus cruzados. Ferrell \& Jenkins (1998), avaliando animais taurinos e seus cruzados sugeriram eficiências entre 65 e 69\%, que também estão de acordo com esse trabalho. Utilizando o mesmo processo interativo, os valores de $\mathrm{k}_{\mathrm{m}}$ sugeridos pelo NRC (2000) e BR-CORTE (2006) de 65 e 63\%, respectivamente.

Embora a maioria dos trabalhos tenha sugerido que a eficiência de uso da energia metabolizável para mantença seja constante e que fique na faixa sugerida por Ferrell \& Jenkins (1998), existem outros autores que sugerem uma eficiência dependente da dieta ofertada e/ou do grau de maturidade do animal.

Garret (1983) dá suporte à ideia de que com maiores níveis de concentrado o animal teria maior produção de propionato, com consequente diminuição na produção de acetato, proporcionando uma maior eficiência de uso da energia metabolizável. De acordo com o autor, esse aumento na eficiência é relevante tanto na eficiência de ganho como de mantença, sendo mais pronunciada para a eficiência de ganho, e utilizou um trabalho desenvolvido por Blaxter \& Wainman (1964) para dar suporte à sua hipótese, onde foram observados aumentos no $\mathrm{k}_{\mathrm{m}}$ e no $\mathrm{k}_{\mathrm{g}}$ quando a porcentagem de milho da dieta aumentou.

Dividindo-se os animais deste experimento de acordo com a dieta recebida (1 ou $2 \%$ do PV em oferta de concentrado), e procedendo os mesmos processos descritos anteriormente para estimação das exigências de energia líquida e metabolizável para mantença, obtêm-se eficiências de 67,3e $67,2 \%$ para animais recebendo 1 ou $2 \%$ do PV em concentrado.

Como os animais em mantença foram utilizados para o cálculo das eficiências das duas dietas, não foi possível testar o efeito de tratamento sobre a eficiência de uso da energia metabolizável para ganho. Entretanto, mesmo sem a análise estatística, é possível afirmar que esses não corroboram com as propostas de Garrett \& Johnson (1983), onde a dieta influenciaria o $\mathrm{k}_{\mathrm{m}}$.

Apesar de dividir a eficiência de ganho $\left(\mathrm{k}_{\mathrm{g}}\right)$ de acordo com a dieta ofertada aos animais, o BR-CORTE (2006), assim como outros sistemas de exigências nutricionais, considera um valor fixo de $\mathrm{k}_{\mathrm{m}}$, o que leva a crer que se realmente há algum fator influenciando fortemente $\mathrm{o} \mathrm{k}_{\mathrm{m}}$, o mesmo ainda não foi detectado e modelado.

Uma terceira forma de estimar as exigências de energia metabolizável para mantença seria avaliar o consumo em função da variação de proteína e gordura no corpo de cada animal. Mais uma vez, não foram encontrados efeitos de grupo genético sobre nenhum dos coeficientes do modelo proposto, dessa forma, foi obtida uma equação conjunta: $\operatorname{CEM}\left(\mathrm{Mcal} / \mathrm{kgPCVZ}{ }^{0,75} / \mathrm{dia}\right)=0,154( \pm 0,019)+3,744( \pm 1,105)$ $\times \Delta_{\text {prot }}+1,3258( \pm 0,213) \times \Delta_{\text {gord }}$ em que CEM = consumo de energia metabolizável; $\Delta_{\text {prot }}=$ variação de energia na forma de proteína (Mcal/PCVZ $0,75 /$ dia); e $\Delta_{\text {gord }}=$ variação de energia na forma de gordura (ou extrato etéreo).

O intercepto desse modelo representa a exigência de energia metabolizável para mantença (154,0 kcal/PCVZ 0,75/dia). Existem controvérsias quanto ao uso desse modelo para estimar a $\mathrm{EM}_{\mathrm{m}}$, pois o mesmo não utiliza animais em mantença para estimar os parâmetros. Portanto, a partir desse modelo, a $\mathrm{EM}_{\mathrm{m}}$ fica sempre superestimada.

Contudo, os métodos tradicionais também são questionados a partir do momento que a adaptação do animal à condição de manutenção faz com que o animal possa ter suas exigências diminuídas por redução de tamanho dos órgãos e vísceras. Essa redução causa diminuição da produção de calor do animal, já que órgãos e vísceras são os maiores responsáveis pelo metabolismo do animal, ou seja, pela produção de calor, que é utilizada para estimar as exigências líquidas e metabolizáveis de mantença.

O inverso dos coeficientes da equação acima citada mostra a eficiência dos animais de conversão de proteína e gordura em energia $\left(\mathrm{k}_{\text {prot }} \mathrm{e} \mathrm{k}_{\text {gord }}\right)$. A eficiência de proteína $\left(\mathrm{k}_{\text {prot }}\right)$ para fornecimento de energia foi de $26,71 \%(1 / 3,744)$ e a eficiência de gordura $\left(\mathrm{k}_{\text {gord }}\right)$ foi de $75,43 \%(1 / 1,3258)$.

Paulino (2006) encontrou valores de 22,88 e 66,67\%; Chizzotti et al. (2008), de 34 e 79\%; Owens et al. (1995), de 47 e 79\%; Valadares Filho et al. (2005), de 25 e 75\%; e Geay (1984), 20 e 75\%, para $k_{\text {prot }}$ e $k_{\text {gord }}$, respectivamente. Há grande variação na eficiência parcial de uso da proteína, mas não da gordura. Segundo Chizzotti et al. (2008), essa variação no $\mathrm{k}_{\text {prot }}$ ocorre porque sua utilização depende muito do estado fisiológico e nutricional do animal e a renovação proteica dos tecidos. 


\section{Conclusões}

Há efeito do teor de concentrado da dieta sobre a relação peso vivo $\times$ peso de corpo vazio, assim como para a relação ganho de peso corporal $\times$ ganho de peso de corpo vazio. O grupo genético influencia apenas a relação entre os ganhos de peso. A exigência de energia líquida para mantença de animais Nelore, Nelore-Angus ou Nelore-Simental é de 75,8 kcal/PCVZ ${ }^{0,75}$ e a de energia metabolizável é de $112,82 \mathrm{kcal} / \mathrm{PCVZ}^{0,75}$. As eficiências de uso da energia metabolizável para ganho e mantença são de 41,22 e 67,19\%, respectivamente, e as eficiências de deposição da energia na forma de proteína e gordura, de 26,71 e 75,43\%, respectivamente.

\section{Referências}

AGRICULTURAL AND FOOD RESEARCH COUNCIL - AFRC. Energy and protein requirements of ruminants. Agricultural and food research council. CAB International. Wallingford. 1993. 176p.

AGRICULTURAL RESEARCH COUNCIL - ARC. The nutrient requirements of ruminants livestock. London: 1980.

BAKER, J.F.; LONG, C.R.; POSADA, G.A. et al. Comparisson of cattle of a five-breed diallel: size, growth, condition and pubertal characters of second-generation heifers. Journal Animal Science, v.67, n.5, p.1218-1229, 1989.

BLAXTER, K.L.; WAINMAN, F.W. The utilization of energy of different rations by sheep and cattle for maintenance and for fattening. Journal of Agriculture Science, v.63, p.113, 1964.

BULlE, M.L.M.; RIBEIRO, F.G.; LEME, P.R. et al. Desempenho de tourinhos cruzados em dietas de altos teor de concentrado com bagaço de cana-de-açúcar como único volumoso. Revista Brasileira de Zootecnia, v.31, n.1, p.444-450, 2002.

CHIZZOTTI, M.L.; TEDESCHI, L.O.; VALADARES FILHO, S.C. A meta-analysis of energy and protein requirements for maintenance and growth of Nellore cattle. Journal of Animal Science, v.86, n.7, p.1588-1597, 2008.

COMMONWEALTH SCIENTIFIC AND INDUSTRIAL RESEARCH ORGANAZATION - CSIRO. Nutrient requirements of domesticated ruminants. Collingwoo: CSIRO Publishing, 2007. 296p.

CRUZ, G.M.; RODRIGUES, A.A.; TULLIO, R.R. et al. Desempenho de bezerros da raça Nelore e cruzados desmamados recebendo concentrado em pastagem adubada de Cynodon dactylon cv. Coastcross. Revista Brasileira de Zootecnia, v.38, n.1, p.139-148, 2009.

DAWSON, L.E.R.; STEEN, R.W.J. Estimation of maintenance energy requirements of beef cattle and sheep. Journal of Agriculture Science, v.131, p.477-485, 1998.

FERRELL, C.L.; JENKINS, T.G. Body composition and energy utilization by steers of diverse genotypes fed a high-concentrate diet during the finishing period: II. Angus, Boran, Brahman, Herefod, and Tuli sires. Journal of Animal Science, v.76, n.2, p.647-657, 1998.
FREITAS, J.A.; QUEIROZ, A.C.; DUTRA, A.R. et al. Eficiência de utilização da energia metabolizável em bovinos Nelore puros e cruzados submetidos a quatro níveis de concentrado na ração. Revista Brasileira de Zootecnia, v.35, n.3, p.894-901, 2006

FULLER, W.A. Measurement error models. New York: John Wiley and Sons, 1987. 440p.

GARRETT, W.N.; JOHNSON, D.E. Nutrition energetics of ruminants. Journal of Animal Science, v.57, n.2, p.478-497, 1983.

INSTITUT NATIONAL DE LA RECHERCHE AGRONOMIQUE INRA. Alimentation des bovins, ovins et caprins. In: JARRIGE, R. (Ed.). Quae, Paris: 2007. 330p.

LEME, P.R.; BOIN, C.; MARGARIDO, R.C.C. et al. Desempenho em confinamento e características de carcaça de bovinos machos de diferentes cruzamentos abatidos em três faixas de peso. Revista Brasileira de Zootecnia, v.29, n.6, p.2347-2353, 2000 (supl. 2).

MARCONDES, M.I.; VALADARES FILHO, S.C.; OLIVEIRA, I.M. et al. Consumo, desempenho e eficiência alimentar de bovinos puros e cruzados recebendo alto ou baixo nível de concentrado. Revista Brasileira de Zootecnia, 2011 (no prelo).

NATIONAL RESEARCH COUNCIL - NRC. Nutrients requirements of beef cattle. 7.ed. Washington, D.C.: 2000. 242p.

PAULINO, P.V.R. Desempenho, composição corporal e exigências nutricionais de bovines Nelore de diferentes classes sexuais. 2006. 167f. Tese (Doutorado em Zootecnia) Universidade Federal de Viçosa, Viçosa, MG.

REGAZZI, A.J. Teste para verificar a identidade de modelos de regressão e a igualdade de parâmetros no caso de dados de delineamentos experimentais. Revista Ceres, v.46, n.266, p.383-409, 1999.

REGAZZI, A.J.; SILVA, C.H.O. Tests para verificar a igualdade de parâmetros e a identidade de modelos de regressão não-linear. I. Dados no delineamento inteiramente causalizado. Revista de Matemática e Estatística, v.22, n.3, p.33-45, 2004.

SAINZ, R.D.; BARIONI, L.G.; PAULINO, P.V.R. et al. Growth patterns of Nellore vs. British beef cattle breeds assessed using dynamic, mechanistic model of cattle growth and composition. In: KEBREAB, E.; DIJKSTRA, J.; BANNINK, A. et al. (Eds). Nutrient digestion and utilization in farm animals: modeling approaches. Wageningen: CABI publishing, 2006. 480p.

SILVA, D.J.; QUEIROZ, A.C. Análise de alimentos (métodos químicos e biológicos). 3.ed. Viçosa, MG: Imprensa Universitária - Universidade Federal de Viçosa, 2002. 165p.

TEDESCHI, L.O.; BOIN, C.; FOX, D.G. et al. Energy requirement for maintenance and growth of Nellore bulls and steers fed high-forage diets. Journal of Animal Science, v.80, n.6, p.1671-1682, 2002

TEDESCHI, L.O.; FOX, D.G.; GUIROY, P.J. A decision support system to improve individual cattle management. 1. A mechanistic, dynamic model for animal growth. Agricultural Systems, v.79, p.171-204. 2004.

VALADARES FILHO, S.C.; PAULINO, P.V.R.; MAGALHÃES, K.A. Exigências nutricionais de zebuínos e tabelas de composição de alimentos - BR CORTE. Viçosa, MG: UFV, Suprema Gráfica Ltda. 2006. 142p.

VALADARES FILHO, S.C.; PAULINO, P.V.R.; SAINZ, R.D. Desafios metodológicos para determinação das exigências nutricionais de bovinos de corte no Brasil. In: REUNIÃO ANUAL DA SOCIEDADE BRASILEIRA DE ZOOTECNIA, 42., 2005, Goiânia. Anais... Goiânia: Sociedade Brasileira de Zootecnia, 2005. p.261-287. 